\title{
Crescimento de mudas de maracujazeiro-amarelo em resposta à adubação com superfosfato simples e pó de rocha
}

\author{
Fabiano Barbosa de Souza Prates ${ }^{1}$, Hermes Soares Veloso ${ }^{2}$, Regynaldo Arruda Sampaio ${ }^{3}$, \\ Geraldo Ribeiro Zuba Junior ${ }^{1}$, Paulo Sérgio Nascimento Lopes ${ }^{3}$, Luiz Arnaldo Fernandes ${ }^{3}$, Marck Morais Maio ${ }^{4}$
}

\section{RESUMO}

Pesquisas feitas com pó de rocha têm mostrado a potencialidade de alguns resíduos em promover o enriquecimento mineral de solos pobres; prática definida como rochagem do solo. Este trabalho teve como objetivo avaliar o crescimento de mudas de maracujazeiro-amarelo (Passiflora edulis Sims f. flavicarpa Deg.) em resposta à adubação com superfosfato simples e pó de rocha. O experimento foi realizado no período de janeiro a abril de 2006, em casa de vegetação do Instituto de Ciências Agrárias da Universidade Federal de Minas Gerais (ICA-UFMG), localizado em Montes Claros/MG. Os tratamentos, em esquema fatorial 2 x 5, no delineamento em blocos casualizados, com três repetições, corresponderam à adição ao substrato de: duas doses de pó de rocha e cinco de superfosfato simples. Foram avaliados: altura das plantas, diâmetro do caule, número de folhas por planta, área foliar, massas de matéria fresca e seca da raiz, massas de matéria fresca e seca da parte aérea e conteúdo de fósforo na planta. Os resultados indicam aumento do crescimento das mudas com o incremento das doses de superfosfato simples e redução do efeito da adubação fosfatada com a adição de pó de rocha ao substrato, possivelmente relacionados a fenômenos de adsorção por formas de ferro amorfo e/ou por carbonatos, considerando que o pó de rocha provém da desintegração de ardósias, mármore e granito. A dose de superfosfato simples sem adição de pó de rocha, para se obterem mudas de maracujá com melhores características, deve ser de 3,0 a 6,5 $\mathrm{kg} \mathrm{m}^{-3}$, enquanto com a adição de pó de rocha, de 6,0 a pelo menos $10,0 \mathrm{~kg} \mathrm{~m}^{-3}$.

Palavras-chave: Passiflora edulis f. flavicarpa, fosfatagem, rochagem.

\section{ABSTRACT}

\section{Growth of yellow passion fruit seedlings in response to simple superphosphate and rock powder waste fertilization}

Research with powder rock have shown the potential of some residues in promoting the mineral enrichment of soils, a practice defined as ground basalt soil. This study aimed to evaluate the growth of seedlings of yellow passion fruit (Passiflora edulis Sims f. flavicarpa Deg.) in response to fertilization with simple superphosphate and powder rock. The experiment was conducted from January to April 2006 in a greenhouse of the Institute of Agricultural Sciences, Federal University of Minas Gerais (UFMG-ICA), located in Montes Claros/MG, Brazil. The treatments were arranged in a factorial $2 \times 5$, in a randomized block design with 3 replicates, corresponding to the addition to the substrate of 2 doses of rock powder and 5 doses of simple superphosphate. The evaluated variables were: plant height, stem

Recebido para publicação em outubro de 2008 e aprovado em fevereiro de 2010

${ }^{1}$ Engenheiros-agrônomos, Mestrandos em Agroecologia. Instituto de Ciências Agrárias, Universidade Federal de Minas Gerais (UFMG), Av. Universitária, nº 1000, Bairro Universitário, 39404-006, Montes Claros, Minas Gerais, Brasil. E-mail: fbprates@gmail.com; juniozuba@yahoo.com.br

${ }^{2}$ Engenheiro-agrônomo. Instituto de Ciências Agrárias, Universidade Federal de Minas Gerais (UFMG), Av. Universitária, nº 1000, Bairro Universitário, 39404-006, Montes Claros, Minas Gerais, Brasil. E-mail: hermesufmg@gmail.com

${ }^{3}$ Engenheiros-agrônomos, Doutores. Instituto de Ciências Agrárias, Universidade Federal de Minas Gerais (UFMG), Av. Universitária, nº 1000, Bairro Universitário, 39404-006, Montes Claros, Minas Gerais, Brasil. E-mail: rsampaio@uafmg.br; psnlopes@ufmg.br; larnaldo@ufmg.br

${ }^{4}$ Geógrafo, Engenheiro-agrônomo. Instituto de Ciências Agrárias, Universidade Federal de Minas Gerais (UFMG), Av. Universitária, nº 1000, Bairro Universitário, 39404-006, Montes Claros, Minas Gerais, Brasil. E-mail: marckmaio.agrogeo@bol.com.br 
diameter, number of leaves per plant, leaf area, root fresh and dry matter, shoot fresh and dry matter and phosphorus content in the plant. The results indicate an increase in seedling growth with increasing levels of simple superphosphate and decrease of the effect of the phosphate fertilizer with the addition of powder rock to the substrate, possibly related to phenomena of adsorption by iron oxides and amorphous and/or carbonates, considering that the powder rock came from the disintegration of slate, marble and granite. The simple superphosphate dose, without the addition of powder rock, to produce better quality seedlings, should range from 3.0 to $6.5 \mathrm{~kg} \mathrm{~m}^{-3}$, whereas with the addition of powder rock, should range from 6.0 to at least $10.0 \mathrm{~kg} \mathrm{~m}^{-3}$.

Key words: Passiflora edulis f. flavicarpa, phosphorus fertilizers, rock fertilizers.

\section{INTRODUÇÃO}

A adição de rochas trituradas ao solo com finalidades agrícolas tem dado bons resultados para algumas culturas, principalmente as rochas de origem máfica, mais rica em elementos essenciais (Amparo, 2003; Silverol \& Machado Filho, 2007; Silva et al., 2008). Theodoro et al. (2002) destacam experiências bem sucedidas com essa prática em que a dupla fertilização de culturas com NPK e rochagem significou ganhos tanto em produtividade quanto econômicos, uma vez que uma quantidade bem menor de fertilizantes químicos foi aplicada; e tendo como vantagem a diminuição de impactos ambientais. Além disso, Theodoro (2000) afirma que experimentos com rochagem e compostagem têm dado bons resultados para algumas culturas de ciclo curto, como a da berinjela, do rabanete e do repolho. Também, Silva et al. (2008) destacam os mesmos efeitos positivos sobre espécies de ciclo longo, como o Gonçalo-Alves, em área degradada. Osterroht (2003) relata que a eficiência no aproveitamento desses minerais é maior quando a sua aplicação é feita junto com esterco, que aumenta a atividade biológica e a disponibilidade de nutrientes no solo.

O fósforo é reconhecidamente um dos elementos mais importantes para o metabolismo vegetal, sendo essencial para o estabelecimento e desenvolvimento das plantas, pois melhora o sistema radicular e a parte aérea (Gonçalves et al., 2000). Quando aplicado na quantidade adequada, estimula a germinação, o desenvolvimento das raízes e melhora a produção das plantas (Knapik, 2005). Gomes e Paiva (2004) complementam que o adequado suprimento desse elemento é importante no início do crescimento da planta para a formação dos primórdios vegetativos, uma vez que as raízes de plantas jovens absorvem fosfato muito mais rapidamente do que raízes de plantas mais velhas.

O maracujá-amarelo (Passiflora edulis f. flavicarpa) tornou-se uma espécie de importância econômica dentre as frutas tropicais, devido à elevada cotação do seu suco no mercado internacional e da fruta fresca no mercado interno. Para o sucesso na sua exploração é importante a produção de mudas de boa qualidade, sendo fundamental a redução de custos utilizando-se formas alternativas de fertilização (Pio et al., 2004). Knapik (2007), em trabalho com produção de mudas de pessegueiro-bravo (Prunus sellowii Koehne), recomenda o uso de pó de rocha de basalto que proporciona mudas de boa qualidade e com boa acumulação de Ca, Mg, B, Cu e Fe em suas folhas.

Diante do exposto, este trabalho teve como objetivo avaliar o crescimento de mudas de maracujazeiro amarelo (Passiflora edulis f. flavicarpa) em resposta à adubação do substrato com superfosfato simples e pó de rocha.

\section{MATERIAL E MÉTODOS}

O experimento foi realizado com mudas de maracujazeiro amarelo (Passiflora edulis f. flavicarpa) no período de janeiro a abril de 2006, em casa de vegetação do Instituto de Ciências Agrárias da Universidade Federal de Minas Gerais (ICA-UFMG), localizado em Montes Claros/MG.

Os tratamentos, em esquema fatorial $2 \times 5$, no delineamento em blocos casualizados, com três repetições, corresponderam a duas doses de pó de rocha (0 e 20 kg m3 de substrato) combinadas com cinco doses de superfosfato simples $\left(1,25 ; 2,5 ; 5,0 ; 7,5\right.$; e $10,0 \mathrm{~kg} \mathrm{~m}^{-3} \mathrm{de}$ substrato).

Foram utilizadas amostras de subsolo de um Latossolo Vermelho-Amarelo (três partes) e de esterco curtido (uma parte), ambos peneirados em peneira de $20 \mathrm{~mm}$. Após ser bem misturado, submeteu-se o substrato ao solarizador por um período de 24 horas, para eliminação de patógenos. Após essa etapa, sobre uma lona, dividiu-se o substrato em 30 partes iguais, com volume de seis litros, e acrescentou-se $0,5 \mathrm{~kg} \mathrm{~m}^{-3}$ de cloreto de potássio e as doses corres- 
pondentes aos tratamentos de pó de rocha e de superfosfato simples, acondicionando-se em seguida, o substrato pronto em sacos de polietileno para mudas de volume igual a dois litros.

Para obtenção das sementes, foram selecionadas plantas de bom estado vegetativo, livre de doenças e que não apresentavam queda prematura de frutos e flores; coletaram-se frutos de bom tamanho, de forma arredondada, completamente maduros, com mais de $150 \mathrm{~g}$ de peso cada um, suculentos, de casca lisa e pouco espessa, e homogêneos. As sementes foram armazenadas em recipiente de vidro, onde sofreram fermentação à sombra, por cinco dias. Logo após esse processo, as sementes foram lavadas em uma peneira com água corrente para separá-las do arilo e postas para secar à sombra.

Semearam-se seis sementes de maracujá por saco e, após a germinação (20 dias), foi promovido o desbaste, deixando-se duas plantas por saco. A unidade experimental foi composta por seis sacos contendo duas mudas cada, totalizando 12 mudas por parcela. Todo o experimento foi composto por 30 parcelas, com 360 mudas. Decorridos 60 dias da germinação, foi coletada a biomassa da parte aérea e das raízes para ser submetida à análise.

Mediu-se o diâmetro do caule a uma altura de $2 \mathrm{~cm}$ a partir do nível do substrato. Tomando o caule como referência, foi medida a altura da planta, iniciando-se a partir do nível do substrato até a ponta da última gema apical. Aárea foliar das plantas foi medida de acordo com técnicas recomendadas por Benincasa (2003). Foi contado o número de folhas simples e completas de todas as plantas, iniciandose pela base até se chegar ao ápice da planta, calculandose o número médio de folhas por planta para cada unidade experimental. Determinou-se a massa de matéria fresca da parte aérea a partir do corte da planta rente ao solo. Para análise da massa de matéria fresca das raízes foram retirados os sacos de polietileno, lavando-se o substrato, com auxílio de jatos de água e uma peneira de $5 \mathrm{~mm}$. O excesso de água nas raízes foi retirado com papel-toalha e elas foram pesadas logo em seguida. A secagem da parte aérea e das raízes foi feita em estufa a $65^{\circ} \mathrm{C}$, por 72 horas. Determinou-se o teor de fósforo das amostras, promovendo-se a sua digestão ácida e realizando-se a dosagem segundo as técnicas recomendadas por Tedesco et al. (1995).

Todos os dados obtidos foram submetidos à análise de variância, sendo as médias das variáveis referentes às doses de pó de rocha comparadas pelo teste de Tukey, a 5\% de probabilidade, e as médias das variáveis referentes às doses de superfosfato, ajustadas a modelos de regressão. O critério para a escolha das equações de regressão foi o maior coeficiente de determinação ajustado, e o teste de significância dos coeficientes da equação até 10\% de probabilidade foi realizado pelo teste $t$.

\section{RESULTADOS E DISCUSSÃO}

Todas as variáveis estudadas tiveram interação entre as doses de fósforo aplicadas e as de pó-de-rocha, exceto o diâmetro do caule, que não diferiu entre os tratamentos e nem respondeu à interação entre os fatores, apresentando valor médio total de 4,02 mm. A massa de matéria fresca da raiz, por outro lado, sofreu apenas o efeito das doses de fósforo aplicadas, não tendo sido constatada interação entre os fatores em estudo.

De acordo com as Tabelas 1 e 2, observa-se que para as variáveis em que houve interação entre as doses de fósforo e pó de rocha, a diferença ocorreu justamente na menor dose de fósforo aplicada, sendo os melhores valores obtidos na ausência do pó de rocha, o que sugere redução na disponibilidade desse elemento com a aplicação do resíduo, possivelmente associada à adsorção do fósforo por formas de ferro amorfo e/ ou por carbonatos, uma vez que o pó de rocha é originário da desintegração de rochas como ardósias, mármore e granito. Isso está de acordo com Novais \& Smyth (1999) e Moreira et al. (2006), os quais afirmam que o fósforo é encontrado adsorvido à superfície dos constituintes minerais do solo ou em minerais cristalinos e amorfos de ferro. Raij (1981) também trata essa questão afirmando que o fósforo tem tendência a formar diversos compostos de solubilidade muito baixa com ferro e cálcio, sendo essa afinidade a razão pela qual o fósforo inorgânico ocorre ligado a esses elementos. Também a ligação pode se dar em solução, com íons formando precipitados, ou pela adsorção de fosfatos na superfície de partículas ou de carbonatos de cálcio, como ocorre em solos calcários.

Observa-se na Figura 1a que a altura da planta aumentou com o aumento das doses de superfosfato simples, atingindo o valor máximo de 28,86 cm na ausência de pó de rocha com a aplicação de 4,33 $\mathrm{kg} \mathrm{m}^{-3}$ de superfosfato simples e de 26,88, na presença de pó de rocha com a aplicação de $10 \mathrm{~kg} \mathrm{~m}^{-3}$, dentro do intervalo experimental. Nesse sentido, verifica-se o efeito negativo do pó de rocha em relação ao crescimento da planta, uma vez que, mesmo aplicando mais do que o dobro da dose de fósforo, ainda assim o crescimento foi menor do que aquele observado na ausência desse resíduo.

Em relação ao número de folhas por planta (Figura 1b), houve aumento nos valores dessa variável com o aumento da aplicação de superfosfato simples até 2,95 $\mathrm{kg} \mathrm{m}^{-3}$ na ausência de pó de rocha, proporcionando número máximo de folhas por planta de 10,71. Por outro lado, na presença de pó de rocha somente com a adição de $6,09 \mathrm{~kg} \mathrm{~m}^{-3}$ de superfosfato simples atingiu-se o valor máximo de 10,75 folhas por planta. Também nesse caso, fica evidente que o pó de rocha afetou a disponibilidade de fósforo para as 
Tabela 1. Altura de planta (Alt), número de folhas (NF), área foliar (AF), massa de matéria seca da raiz (MSR), massa de matéria fresca da parte aérea (MFA) e massa de matéria seca da parte aérea (MSA) de mudas de maracujazeiro adubadas com doses de $\mathrm{P}_{2} \mathrm{O}_{5}$ na ausência (SP) ou presença (CP) de pó de rocha no substrato

\begin{tabular}{|c|c|c|c|c|c|c|c|c|c|c|c|c|}
\hline \multirow{2}{*}{$\begin{array}{l}\mathbf{P}_{2} \mathbf{O}_{5} \\
\left(\mathrm{~kg} \mathrm{~m}^{-3}\right)\end{array}$} & \multicolumn{2}{|c|}{ Alt (cm) } & \multicolumn{2}{|c|}{ NF } & \multicolumn{2}{|c|}{$\mathrm{AF}\left(\mathrm{cm}^{2}\right)$} & \multicolumn{2}{|c|}{ MSR (g) } & \multicolumn{2}{|c|}{ MFPA (g) } & \multicolumn{2}{|c|}{ MSPA (g) } \\
\hline & SP & CP & SP & CP & SP & CP & SP & CP & SP & CP & SP & CP \\
\hline 1,25 & $21,44 a$ & $11,48 \mathrm{~b}$ & $10,87 a$ & 8,24b & $70,44 a$ & 23,91b & $0,67 a$ & $0,36 \mathrm{~b}$ & 9,79a & $4,62 b$ & 3,11a & $1,12 \mathrm{~b}$ \\
\hline 2,50 & $26,47 \mathrm{a}$ & $24,58 a$ & $10,34 a$ & 10,53a & $65,95 a$ & 63,06a & $0,75 a$ & 0,70a & $11,19 a$ & 11,69a & 2,98a & $2,79 a$ \\
\hline 5,00 & $29,64 a$ & $19,04 \mathrm{~b}$ & $10,79 a$ & $10,12 \mathrm{a}$ & $70,22 \mathrm{a}$ & 61,78a & $0,85 a$ & 0,69a & $12,54 a$ & $8,85 \mathrm{~b}$ & $3,25 a$ & $2,69 a$ \\
\hline 7,50 & $24,27 a$ & $27,36 a$ & $10,41 \mathrm{a}$ & $10,75 a$ & $76,21 \mathrm{a}$ & 70,12a & 0,90a & $0,85 a$ & $12,45 \mathrm{a}$ & $12,36 a$ & $3,34 a$ & $3,14 a$ \\
\hline 10,00 & $19,76 a$ & $26,66 a$ & 9,85a & $10,25 a$ & $49,89 a$ & 68,77a & $0,64 a$ & 0,79a & $8,67 \mathrm{~b}$ & $12,38 \mathrm{a}$ & $2,12 \mathrm{a}$ & 3,23a \\
\hline
\end{tabular}

Para cada variável, médias seguidas da mesma letra na horizontal não diferem estatisticamente entre si a 5\% de probabilidade pelo teste de Tukey.

Tabela 2. Massa de matéria fresca total (MFT), massa de matéria seca total (MST), relação da massa de matéria fresca da parte aérea em relação à raiz (MFPR), relação da massa de matéria seca da parte aérea em relação à raiz (MSPR) e conteúdo de fósforo em mudas de maracujazeiro adubadas com doses $\mathrm{P}_{2} \mathrm{O}_{5}$ na ausência (SP) ou presença (CP) de pó de rocha no substrato

\begin{tabular}{|c|c|c|c|c|c|c|c|c|c|c|}
\hline \multirow{2}{*}{$\begin{array}{l}P_{2} \mathbf{O}_{5} \\
\left(\mathrm{~kg} \mathrm{~m}^{-3}\right)\end{array}$} & \multicolumn{2}{|c|}{ MFT (g) } & \multicolumn{2}{|c|}{ MST (g) } & \multicolumn{2}{|c|}{ MFPR } & \multicolumn{2}{|c|}{ MSPR } & \multicolumn{2}{|c|}{ CP (mg por planta) } \\
\hline & SP & $\mathbf{C P}$ & SP & $\mathbf{C P}$ & SP & $\mathbf{C P}$ & SP & $\mathbf{C P}$ & SP & $\mathbf{C P}$ \\
\hline 1,25 & $14,41 \mathrm{a}$ & $7,88 \mathrm{~b}$ & 3,78a & $1,48 b$ & $2,14 a$ & $1,39 b$ & $4,61 \mathrm{a}$ & $2,91 b$ & $8,69 a$ & $2,23 b$ \\
\hline 2,50 & $16,88 a$ & $17,99 a$ & 3,73a & $3,49 a$ & $1,92 \mathrm{a}$ & $1,85 a$ & $3,81 \mathrm{a}$ & $3,95 a$ & $5,95 a$ & $5,85 a$ \\
\hline 5,00 & $20,20 a$ & $15,31 \mathrm{a}$ & $4,10 \mathrm{a}$ & $3,38 a$ & $1,65 a$ & $1,38 \mathrm{a}$ & $3,79 a$ & $3,62 \mathrm{a}$ & $9,11 \mathrm{a}$ & $6,44 a$ \\
\hline 7,50 & $21,05 a$ & $20,28 a$ & $4,24 a$ & $3,99 a$ & $1,48 a$ & $1,57 \mathrm{a}$ & $3,74 a$ & $3,67 a$ & $9,67 \mathrm{a}$ & $9,41 \mathrm{a}$ \\
\hline 10,00 & $14,55 a$ & $18,65 a$ & $2,76 a$ & $4,03 a$ & $1,46 b$ & $2,09 a$ & $3,32 a$ & $3,95 a$ & $5,09 a$ & $7,09 a$ \\
\hline
\end{tabular}

Para cada variável, médias seguidas da mesma letra na horizontal não diferem estatisticamente entre si a 5\% de probabilidade pelo teste de Tukey.

plantas, reduzindo a emissão de folhas nas menores doses desse elemento.

O aumento da altura da planta e do número de folhas com a adição de fósforo ao substrato, independentemente da adição ou não do pó de rocha, está de acordo com os resultados obtidos por Prado et al. (2005), os quais observaram que a aplicação do fósforo na forma de superfosfato triplo incrementou a altura e o número de folhas das mudas de maracujazeiro.

A área foliar (Figura 1c) também aumentou com o aumento da dose de superfosfato simples, atingindo o valor máximo de 73,98 $\mathrm{cm}^{2}$ com a aplicação de 4,71 $\mathrm{kg} \mathrm{m}^{-3}$ desse adubo na ausência de pó de rocha. Na presença desse resíduo, a área foliar máxima atingida foi de $71,82 \mathrm{~cm}^{2}$, com a dose de $6,87 \mathrm{~kg} \mathrm{~m}^{-3}$ de superfosfato simples. De modo semelhante ao ocorrido com o número de folhas, a presença de pó de rocha no substrato afetou significativamente a área foliar das mudas, principalmente nas menores doses de fosfato.

De acordo com a Figura 2a, observa-se que a massa de matéria fresca da raiz não sofreu efeito da interação entre os fatores em estudo e aumentou com o incremento das doses de superfosfato simples, atingindo o valor máximo de 7,93 g com a aplicação de 6,51 $\mathrm{kg} \mathrm{m}^{-3}$ desse adubo. Por outro lado, em relação à massa de matéria seca da raiz, houve interação entre as doses de fósforo e de pó de rocha (Figura 2b). Observa-se que, na ausência de pó de rocha, o valor máximo de massa de matéria seca da raiz foi de 0,89 g com a aplicação de $5,67 \mathrm{~kg} \mathrm{~m}^{-3}$ de superfosfato simples. Mesmas tendências foram observadas por Peixoto (1986) e Machado (1998), os quais constataram efeito positivo da aplicação de fósforo na produção de massa de matéria seca das raízes de mudas de maracujazeiro-amarelo. Já na presença de pó de rocha, o valor máximo foi de 0,82 g com a aplicação de 7,47 $\mathrm{kg} \mathrm{m}^{-3}$ desse adubo. Também nesse caso, constata-se o efeito negativo do pó de rocha em relação à produção de massa de matéria seca das raízes, que é uma característica importante para a muda, considerando-se que sistemas radiculares mais desenvolvidos aumentam a sua resistência no campo após o plantio.

Com base na Figura 3a, observa-se que a massa de matéria fresca da parte aérea, na ausência de pó de rocha, aumentou com o incremento das doses de superfosfato simples, atingindo o valor máximo de 12,87 g com a aplicação de $5,38 \mathrm{~kg} \mathrm{~m}^{-3}$ desse adubo. Por outro lado, com a aplicação do pó de rocha, o valor máximo dentro do intervalo experimental foi de 12,37 g com a aplicação de 10,00 $\mathrm{kg} \mathrm{m}^{-3}$ de superfosfato simples. Resultados semelhantes foram observados para a massa de matéria seca da parte aérea (Figura 3b), em que, na ausência de pó de rocha, o valor máximo foi de 3,36 g com a aplicação de 4,72 $\mathrm{kg} \mathrm{m}^{-3}$ de superfosfato simples, enquanto com a aplicação do pó de rocha, o maior valor foi de 3,21 g com a aplicação de 

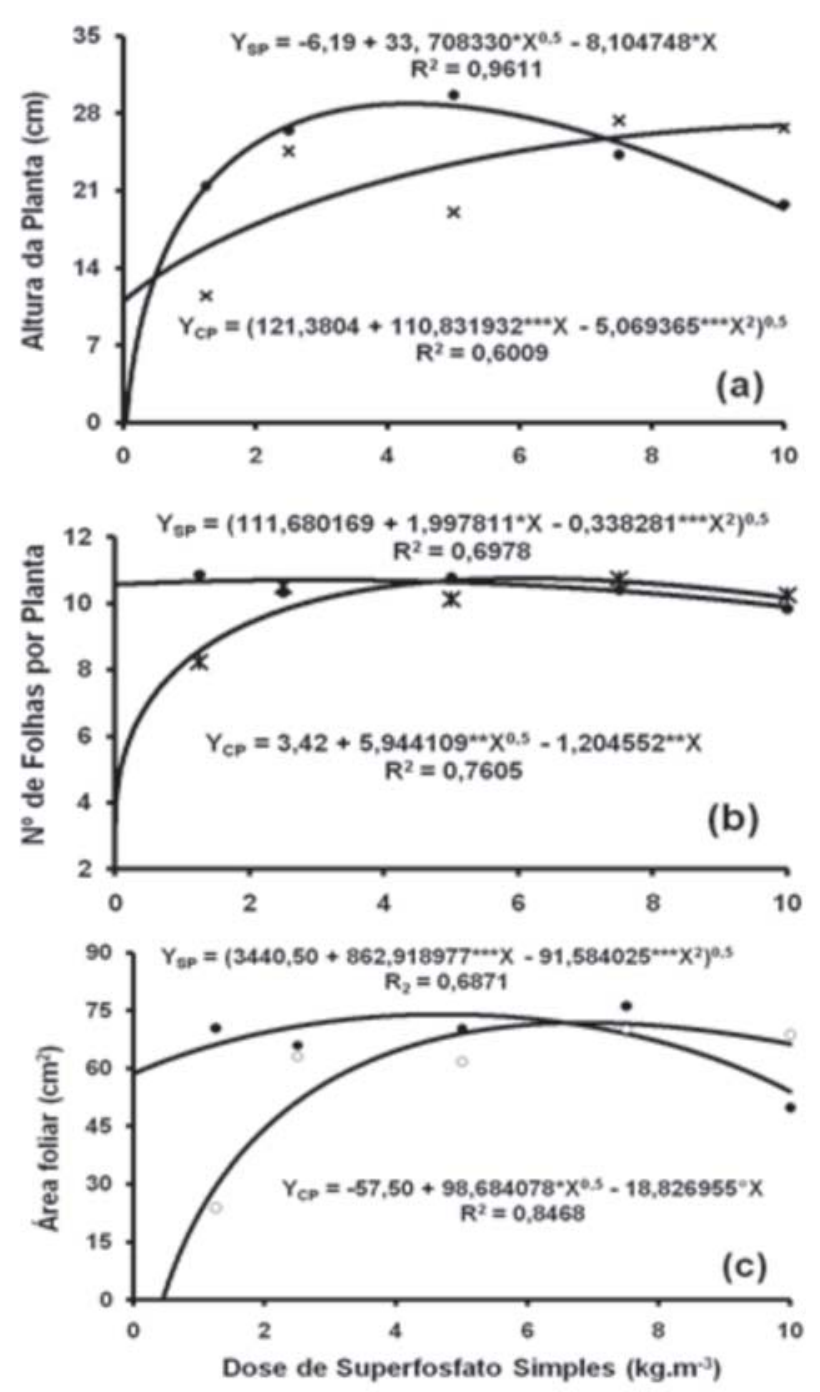

Figura 1. Altura de planta (a), número de folhas (b) e área foliar (c) de mudas de maracujazeiro em função das doses de superfosfato simples na presença (CP) e ausência (SP) de pó de rocha adicionado ao substrato.

$\circ$, *,** $\mathrm{e}^{* * *}$ : Significativos a 5,1 e $0,1 \%$, respectivamente, pelo teste t.

8,87 $\mathrm{kg} \mathrm{m}^{-3}$ do adubo fosfatado. A exemplo do que foi observado para outras características da planta, a aplicação do pó de rocha diminuiu os efeitos da adubação fosfatada.

Em relação à massa de matéria fresca total da planta (Figura 4a), observa-se que houve aumento na sua produção com o incremento das doses de superfosfato simples. Na ausência de pó de rocha, o valor máximo alcançado foi de $21,04 \mathrm{~g}$ com a aplicação de $5,79 \mathrm{~kg} \mathrm{~m}^{-3}$ do adubo fosfatado. Por outro lado, com a aplicação de pó de rocha o valor máximo atingido foi de 19,33 g com a aplicação de 7,28 $\mathrm{kg} \mathrm{m}^{-3}$ de superfosfato simples. De forma similar, a massa de matéria seca total da planta (Figura 4b) aumentou com o incremento das doses de superfosfato simples, atingindo o máximo de 4,04 g na
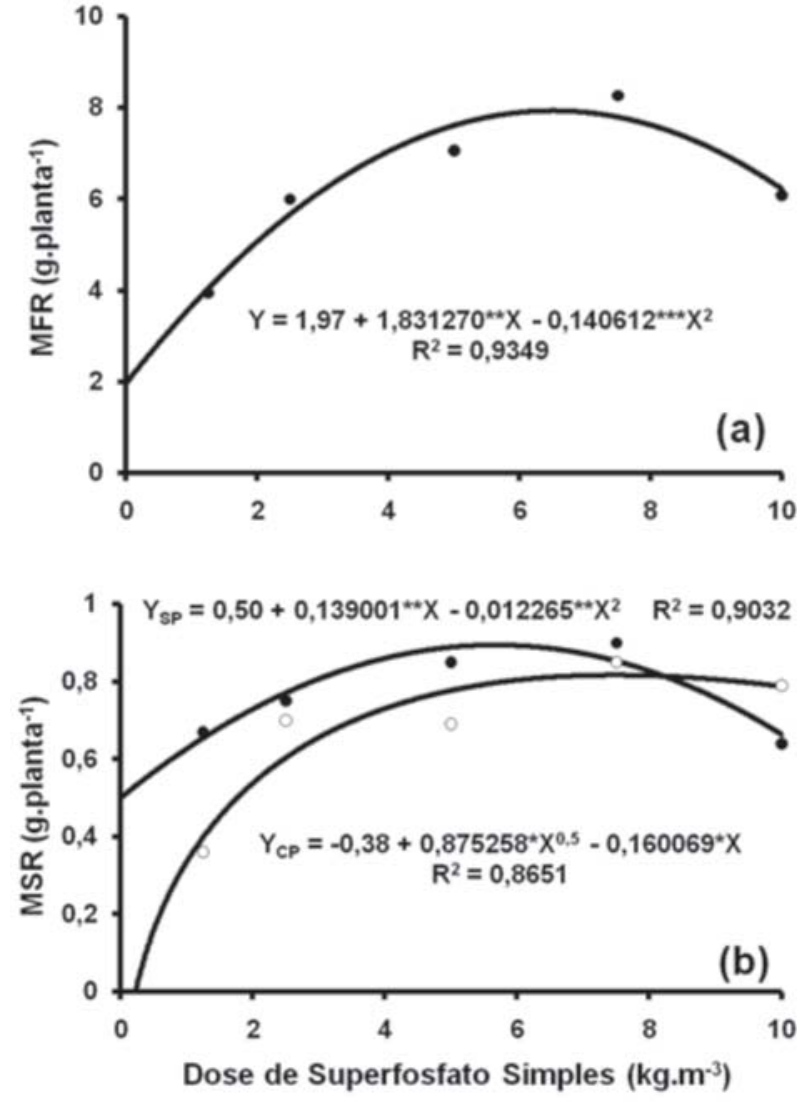

Figura 2. Massas de matéria fresca (a) e seca (b) da raiz de mudas de maracujazeiro em função das doses de superfosfato simples na presença (CP) e ausência (SP) de pó de rocha adicionado ao substrato.

*, ** e $\mathrm{e}^{* * *}$ : Significativos a 5, 1 e $0,1 \%$, respectivamente, pelo teste $\mathrm{t}$.

ausência de pó de rocha com a aplicação de 4,87 g do adubo fosfatado. Com a adição de pó de rocha ao substrato, o valor máximo foi de com a aplicação de 7,69 $\mathrm{kg} \mathrm{m}^{-3}$ de superfosfato simples. Percebe-se que com a adição de pó de rocha ao substrato é necessário aplicar praticamente o dobro da adubação fosfatada para se obter a mesma produção de biomassa verificada na ausência desse resíduo. A exemplo do que ocorreu neste trabalho, efeitos positivos da adubação fosfatada sobre o crescimento em altura, número de folhas, massa de matéria seca da parte aérea e massa de matéria seca total de mudas de maracujazeiro também foram observados por Prado et al. (2005) e Lima et al. (2007).

Observa-se na Figura 5a que na ausência de pó de rocha a relação da massa de matéria fresca da parte aérea/raiz diminuiu com o aumento das doses de fósforo, atingindo o valor mínimo de 1,45 com a aplicação de $8,79 \mathrm{~kg} \mathrm{~m}^{-3}$ de superfosfato simples. Por outro lado, com a aplicação de pó de rocha o valor mínimo foi de 1,46 com a aplicação de $4,15 \mathrm{~kg} \mathrm{~m}^{-3}$ de adubo fosfatado. Para a relação da massa de matéria seca da parte aé- 

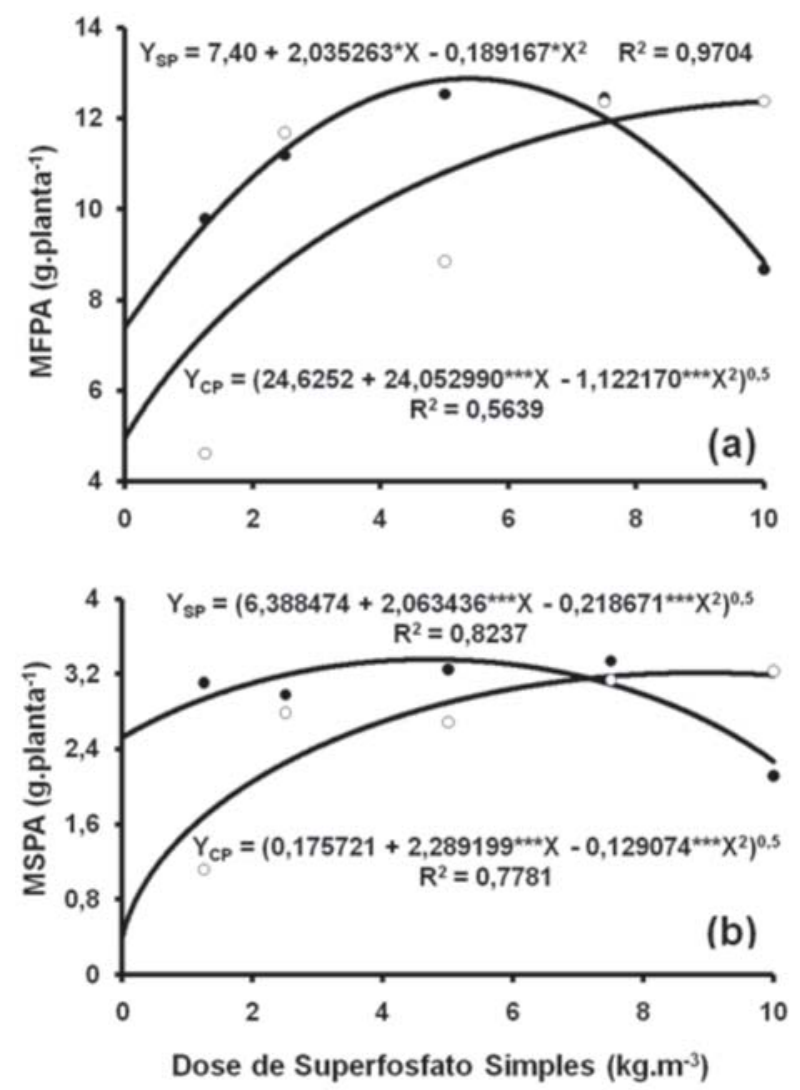

Figura 3. Massas de matéria fresca (a) e seca (b) da parte aérea de mudas de maracujazeiro em função das doses de superfosfato simples na presença (CP) e ausência (SP) de pó de rocha adicionado ao substrato.

* e ***: Significativos a 5 e $0,1 \%$, respectivamente, pelo teste $t$.

rea/raiz (Figura 5b), na ausência de pó de rocha houve redução da relação com o aumento das doses de superfosfato simples, atingindo o mínimo de 3,43 com a aplicação de $10 \mathrm{~kg} \mathrm{~m}^{-3}$ desse adubo. Entretanto, com a aplicação do pó de rocha houve aumento da relação da massa seca da parte aérea/raiz, sendo o mínimo da relação de 3,06 obtido com a aplicação de $0 \mathrm{~kg} \mathrm{~m}^{-3}$ de superfosfato simples.

Embora a menor relação parte aérea/raiz seja uma característica desejável para se obter muda mais resistente para o plantio no campo, nesse caso a menor relação observada na presença de pó de rocha parece estar mais associada a uma deficiência inicial de fósforo na planta. Essa deficiência, portanto, afetou mais a parte aérea do que as raízes, conforme observado nas Figuras 2 e 3, onde se constatou que em relação ao peso da massa de matéria fresca das raízes sequer houve influência do pó de rocha, além do fato de a dose que resultou em valor máximo do peso da massa de matéria seca, com a adição de pó de rocha, ser mais próxima daquela sem a adição desse resíduo, comparativamente às doses referentes às massas de matéria fresca e seca da parte aérea.
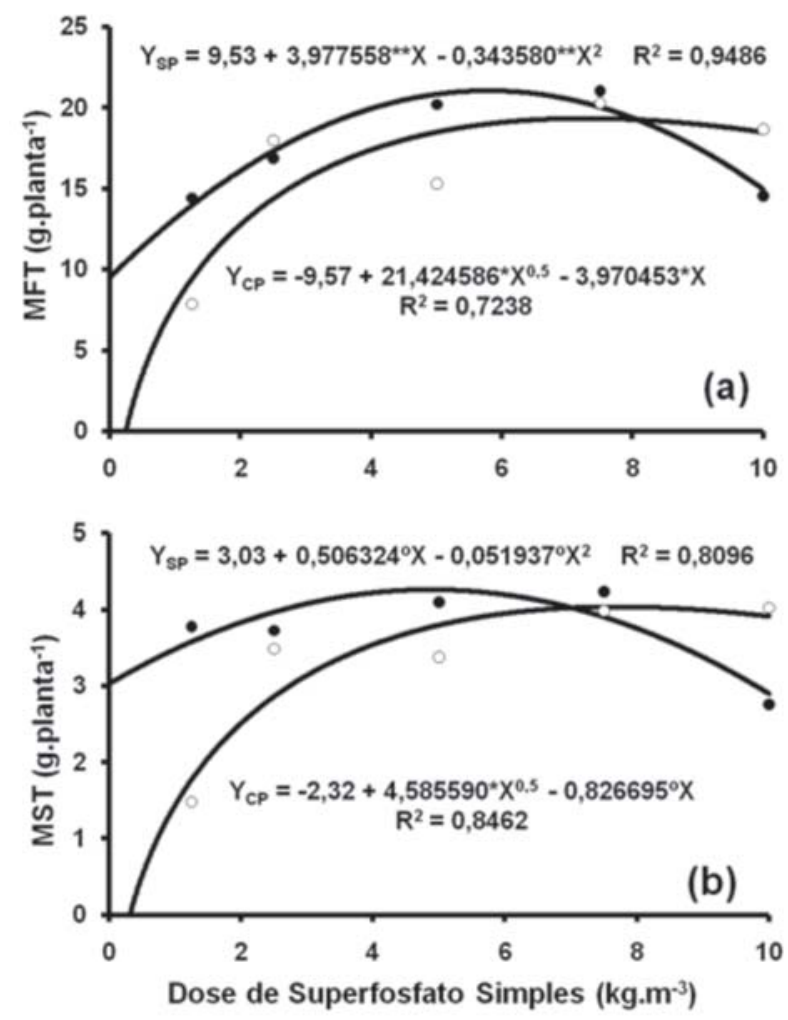

Figura 4. Massas de matéria fresca (a) e seca (b) total de mudas de maracujazeiro em função das doses de superfosfato simples na presença (CP) e ausência (SP) de pó de rocha adicionado ao substrato.

$\circ$, * e**: Significativos a 10, 5 e 1\%, respectivamente, pelo teste t.

Na Figura 6, observa-se que o conteúdo de fósforo aumentou com a adição de superfosfato simples ao substrato. Na ausência de pó de rocha, o valor máximo foi de $9,50 \mathrm{mg}$ por planta com a dose de $6,21 \mathrm{~kg} \mathrm{~m}^{-3} \mathrm{de}$ adubo fosfatado, enquanto com a adição de pó de rocha o valor máximo foi de $8,53 \mathrm{mg}$ por planta com a dose de $7,28 \mathrm{~kg} \mathrm{~m}^{-3}$ do mesmo adubo. Resultados semelhantes foram encontrados por Prado et al. (2005), quando aplicaram fósforo ao substrato e obtiveram efeito linear crescente no teor de fósforo na parte aérea e nas raízes em mudas de maracujazeiro-amarelo. Respostas positivas de mudas de maracujazeiro à aplicação de fósforo também foram relatadas por autores como Machado (1998) e Peixoto et al. (1999).

Os resultados indicam menor efeito da adubação fosfatada quando adicionada juntamente com pó de rocha de marmoraria no substrato para produção de mudas de maracujá, conforme verificado também para as demais características da planta. De acordo com Malavolta (2004), as plantas não conseguem aproveitar mais que $10 \%$ do fósforo total aplicado, devido ao fenômeno de fixação desse elemento. Portanto, é possível que esses menores teores estejam relacionados a fenômenos de adsorção por 
formas de ferro amorfo e/ou carbonatos, provenientes da desintegração de ardósias, mármores e granitos, cujos resíduos foram utilizados neste experimento (Resende et al., 1985).
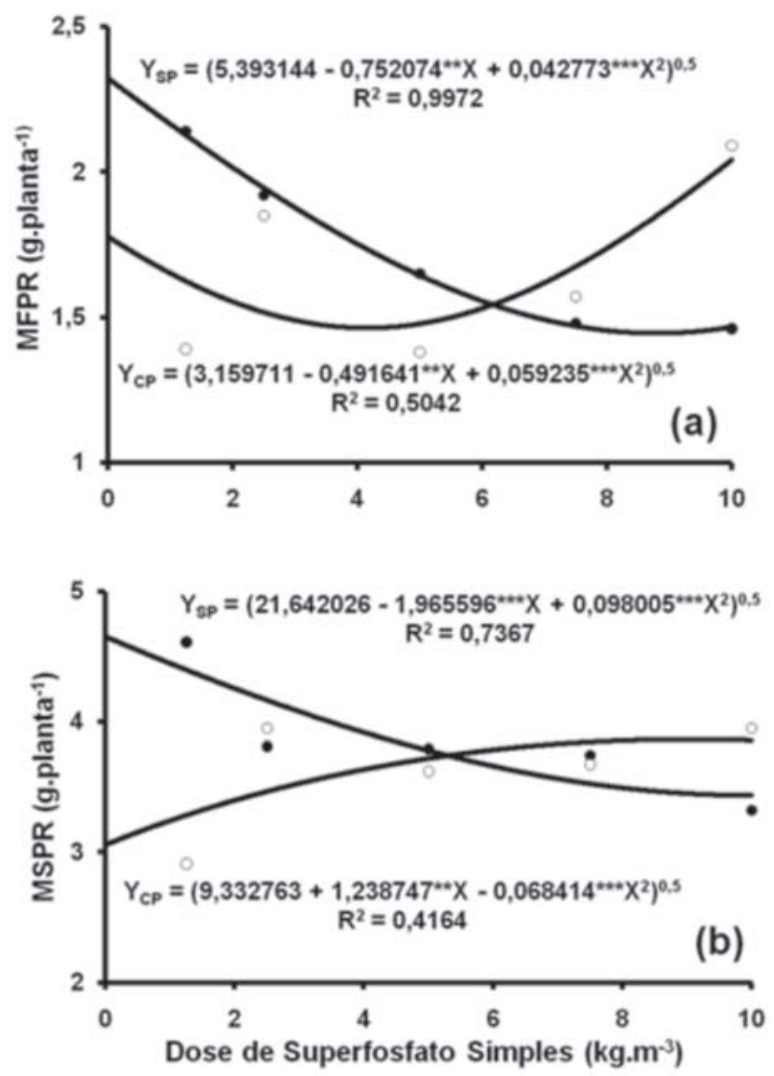

Figura 5. Relação massa de matéria fresca da parte aérea:raiz (a) e massa de matéria seca da parte aérea:raiz (b) de mudas de maracujazeiro em função das doses de superfosfato simples na presença (CP) e ausência (SP) de pó de rocha adicionado ao substrato.

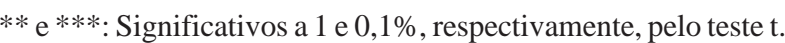

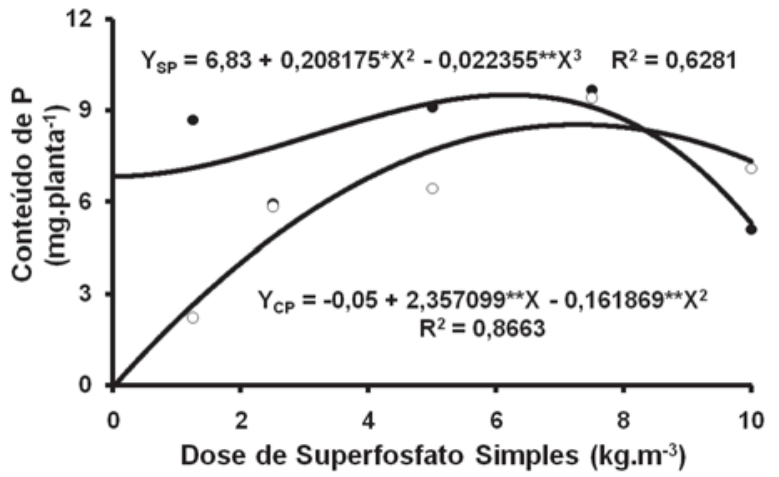

Figura 6. Conteúdo de fósforo de mudas de maracujazeiro em função das doses de superfosfato simples na presença (CP) e ausência (SP) de pó de rocha adicionado ao substrato.

* $\mathrm{e}^{* *}$ : Significativos a 5 e $1 \%$, respectivamente, pelo teste $\mathrm{t}$.

\section{CONCLUSÕES}

Com os resultados obtidos nas condições em que foi desenvolvido este experimento, conclui-se que:

A adição de pó de rocha ao substrato para produção de mudas de maracujá reduz o efeito da adubação fosfatada.

A dose de superfosfato simples a ser adicionada ao substrato sem adição de pó de rocha de marmoraria para se obterem mudas de maracujá com melhores características deve estar entre 3,0 e 6,5 $\mathrm{kg} \mathrm{m}^{-3}$.

A dose de superfosfato simples a ser adicionada ao substrato, juntamente com pó de rocha de marmoraria, para se obterem mudas de maracujá com melhores características deve estar entre 6,0 e $10,0 \mathrm{~kg} \mathrm{~m}^{-3}$.

\section{REFERÊNCIAS}

Amparo A (2003) Farinha de rocha e biomassa. Agroecologia Hoje, 4:10-12.

Benincasa MMP (2003) Análise de crescimento de plantas: noções básicas. 2 ed., Jaboticabal, Funep. 41p.

Gomes JM \& Paiva H (2004). Viveiros florestais: propagação sexuada. Viçosa, Editora da UFV. 116p.

Gonçalves JLM, Santareli EG, Moraes Neto, SP, Manara, MP (2000) Produção de mudas de espécies nativas: substrato, nutrição, sombreamento e fertilização. In: Gonçalves, J.L. M.; Benedetti, V. (Eds.). Nutrição e fertilização florestal. Piracicaba, IPEF, p.309-350.

Knapik JG (2005) Utilização do pó de basalto como alternativa à adubação convencional na produção de mudas de Mimosa scabrella Benth e Prunus sellowii Koehne. Dissertação de Mestrado. Universidade Federal do Paraná, Curitiba, 163p.

Lima RAF, Mendonça V, Tosta MS, Reis LL, Biscaro GA, Chagas EA (2007) Fósforo e zinco no crescimento de mudas de maracujazeiro-amarelo. Pesquisa Agropecuária Tropical, 37: 251-256.

Machado RAF (1998) Fósforo e zinco na nutrição e crescimento de mudas de maracujazeiro amarelo (Passiflora edulis f. flavicarpa Deg.). Dissertação de Mestrado. Universidade Federal de Lavras, Lavras, 93p.

Malavolta E (2004) O fósforo na planta e interações com outros elementos. In: Yamada, T; Stipp e Abdalla SR (Orgs.) Fósforo na Agricultura Brasileira. Piracicaba, Potafos, p.35-106.

Moreira FLM, Mota FOB, Clemente CA, Azevedo BM de, Bonfim GV do (2006) Adsorção de fósforo em solos do Estado do Ceará. Revista Ciência Agronômica, 37: 7-12.

Novais RF \& Smyth TJ (1999) Fósforo em solo e planta em condições tropicais. Viçosa, Universidade Federal de Viçosa, 399p.

Osterroht M (2003). Rochagem para quê? Agroecológica, 20: 12-15.

Peixoto JR (1986) Efeito da matéria orgânica, superfosfato simples e do cloreto de potássio na formação de mudas de maracujazeiro amarelo (Passiflora edulis Sims). Dissertação de mestrado. Escola Superior de Agricultura de Lavras, Lavras, 101p.

Peixoto JR, Paiva Junior MC, Angelis B, Oliveira JA (1999) Adubação orgânica e fosfatada no desenvolvimento de mudas de maracujazeiro amarelo (Passiflora edulis Sims f. flavicarpa Deneger). Revista Brasileira de Fruticultura, 21:49-51. 
Pio R, Gontijo TCA, Ramos JD, Carrijo EP, Toledo M, Visioli EL, Tomasetto F (2004) Produção de mudas de maracujazeiro amarelo em diferentes substratos. Revistas Brasileiras de Agrociência, 10: 523-525.

Prado R M, Vale DW, Romualdo LM (2005) Fósforo na nutrição e produção de mudas de maracujazeiro. Acta Scientiarum, 27: 493-498.

Raij BV (1981) Avaliação da fertilidade do solo. Piracicaba, Instituto da potassa \& fosfata. 142p.

Resende JM do A, Braga JM, Amaral F de AL (1985) Índice de sorção de fósforo: isotermas, capacidade tampão e sorção de ponto único. Revista Ceres, 32: 179-195.

Silva EA da S, Cassiolato AMR, Maltoni KL, Scabora, MH (2008) Efeitos da rochagem e de resíduos orgânicos sobre aspectos químicos e microbiológicos de um subsolo exposto e sobre o crescimento de Astronium fraxinifolium Schott. Revista Árvore, 32: 323-333.
Silverol AC \& Machado Filho L (2007) Utilização de pó de granito e manto de alteração de piroxenito para fertilização de solos. Revista Brasileira de Agroecologia, 2: 703-707.

Tedesco MJ, Gianello C, Bissani CA, Bohnen H, Volkweiss SJ (1995) Análise de solo, plantas e outros materiais. Porto Alegre, UFRGS. 174p. (Boletim Técnico, 5).

Theodoro SCH, Leonardos OH, Dubois AM (2002) Rochagem e compostagem: uma forma ambientalmente correta de recuperar e fertilizar áreas degradadas. In: Suzi Huff Theodoro SH (Org.). Conflitos e Uso Sustentável dos Recursos Naturais. Rio de Janeiro, Garamond, p.85-102.

Theodoro SM de CH (2000) A fertilização da terra pela terra: uma alternativa para a sustentabilidade do pequeno produtor rural. Tese de Doutorado. Universidade de Brasília, Brasília, 225p. 